\title{
PERENCANAAN PREFABRICATED VERTICAL DRAIN MENGGUNAKAN METODE ELEMEN UNTUK MEMPEROLEH POLA DAN JARAK YANG EFEKTIF
}

\author{
Joshua Michael ${ }^{1}$ dan Aksan Kawanda ${ }^{2}$ \\ ${ }^{1}$ Program Studi Sarjana Teknik Sipil, Universitas Tarumanagara, Jl. Letjen S. Parman No.1 Jakarta \\ Joshuamichaeel@gmail.com \\ ${ }^{2}$ Program Studi Magister Teknik Sipil, Universitas Trisakti, Jl. Kyai Tapa No. 1 Grogol Jakarta Barat, Indonesia \\ Aksan@dtt.untar.ac.id
}

Masuk: 07-08-2020, revisi: 25-07-2020, diterima untuk diterbitkan: 05-08-2020

\begin{abstract}
As a city develops, less areas will be available for constructions. Out of these available lands, a large quantity of areas has low soil bearing capacity and great amount of settlement. For this type of soil, loading is required in order to stabilize it. This will push out porewater contained inside the soil. However, reaching the expected settlement requires a long time, which can be solved by using prefabricated vertical drain to speed up the process. This is possible because prefabricated vertical drain decreases the travel distance of porewater to half of the vertical drain. Calculations for this thesis are done using one dimensional consolidation method, finite element method, and asaoka method for actual data calculation from the field. Using one dimensional consolidation method, with prefabricated vertical drain distance of $1.2 \mathrm{~m}$ in triangular pattern, resulted in settlement level of $2.048 \mathrm{~m}$ for 110 days. Using finite element method resulted in settlement level of $2.604 \mathrm{~m}$ for 120 days. On the other hand, using asaoka method resulted in settlement level of $1.422 \mathrm{~m}$ for 102 days. This difference is caused by lack of depth data from the laboratory.
\end{abstract}

Keywords: soft soil; settlement; porewater; prefabricated vertical drain

\begin{abstract}
ABSTRAK
Semakin berkembangnya jaman maka pembangunan semakin banyak sehingga lahan untuk dilakukannya pembangunan semakin sedikit. Sekarang banyak tanah yang memiliki daya dukung kecil dan penurunan yang besar contohnya seperti tanah lunak. Agar tanah model ini dapat memiliki kondisi yang stabil , maka solusinya diberi beban sehingga air pori dari dalam tanah dapat tertekan keluar. Namun untuk mencapai penurunan yang diinginkan membutuhkan waktu yang cukup lama, disini digunakan metode prefabricated vertical drain untuk mempercepat penurunan. Prefabricated vertical drain disini membuat jarak tempuh air pori tanah yang sebelumnya setebal tanah lunak, menjadi setengah jarak antar prefabricated vertical drain. Perhitungan analisa pada skripsi ini menggunakan metode one dimensional consolidation, metode elemen hingga, dan metode asaoka sebagai perhitungan hasil aktual dari data lapangan. Penurunan total menggunakan metode one dimensional consolidation dengan jarak antar prefabricated vertical drain $1.2 \mathrm{~m}$ dengan pola segitiga sebesar $2.048 \mathrm{~m}$ selama 110 hari, sedangkan dari metode elemen hingga didapatkan penurunan sebesar $2.604 \mathrm{~m}$ selama 120 hari. Dari data settlement recording yang dihitung menggunakan metode asaoka terjadi penurunan sebesar $1.422 \mathrm{~m}$ selama 102 hari. Perbedaan disini disebabkan oleh kurang banyaknya sample kedalaman dari data laboratorium.
\end{abstract}

Kata kunci: tanah lunak; penurunan; air pori; prefabricated vertical drain

\section{PENDAHULUAN}

Semakin berkembangnya jaman semakin banyak juga pembangunan yang terjadi yang secara tidak langsung mengakibatkan kekurangannya lahan tempat pembangunan tersebut. Sehingga, terkadang pembangunan tersebut harus dilakukan pada tanah yang memiliki daya dukung kecil, dengan penurunan yang besar. Permasalahan dalam pembangunan adalah pada tanah-tanah tertentu terdapat lapisan tanah sangat jelek yang tebal. Pada kenyataannya tanah lempung bersifat kurang menguntungkan secara teknis untuk mendukung suatu pekerjaan konstruksi (Anissa Maria Hidayati, 2006).

Demi mencapai suatu elevasi yang sesuai dengan rencana pembangunan maka penimbunan umum untuk dilakukan pada suatu proyek, namun hal ini akan mengakibatkan terjadinya tegangan tambahan pada tanah. Tegangan tambahan pertama akan dipikul oleh air pori yang ada di tanah karena sifat incompressible air. Sehingga 
menyebabkan keluarnya air pori tanah, setelah itu tanah padatlah yang menerima tegangan yang sebelumnya dipikul air pori. Hal inilah yang mengakibatkan terjadinya penurunan konsolidasi.

Konsolidasi biasanya tidak terjadi secara horizontal karena pada lapisan yang terkena beban tidak mampu bergerak horizontal, namun konsolidasi umumnya terjadi secara vertikal. Namun pada skripsi ini, akan diterapkan metode Prefabricated vertical drain dimana dipasang saluran untuk air pori dapat mengalir sehingga mempercepat terjadinya konsolidasi.

Pada studi kali ini, saya akan menganalisis penurunan yang terjadi pada tanah lunak disini yang diakibatkan oleh timbunan yang ada setelah diterapkannya Prefabricated vertical drain dengan pola segitiga pada jarak jarak tertentu.

\section{Prefabricated vertical drain (PVD)}

Tanah lunak, seperti lunak di sekitar muara dan lempung di daerah laut, gambut, dan tanah yang ada di area rawa, yang biasa dijumpai di sepanjang daerah pantai di seluruh dunia, sangat mudah di mampatkan di alam dan memiliki sifat geoteknik yang tidak diinginkan, seperti kadar air alami yang tinggi (dekat dengan batas cairan), kekuatan geser rendah yang tidak terkuras dan konduktivitas hidrolik rendah (Sakleshpu, Salgado, \& Prezzi, 2018). Oleh karena itu, struktur yang dibangun pada tanah ini menghadapi masalah stabilitas dan kemudahan dalam pelayanan jika tidak diambil tindakan untuk memperbaikinya. Meskipun pondasi tiang pancang dapat digunakan dalam beberapa situasi untuk mengatasi masalah ini, mereka mungkin terlalu mahal, terutama untuk mendukung tanggul dan bangunan bertingkat rendah. Dalam kasus seperti itu, tanah dalam zona transfer beban struktur perlu ditingkatkan untuk membuat tanah cocok untuk mendukung beban yang diterapkan. Perbaikan tanah pada dasarnya berarti meningkatkan kekuatan geser dan mengurangi kompresibilitas tanah ke tingkat yang diinginkan. Stabilisasi tanah lunak sebelum konstruksi dengan menggunakan beban tambahan sendiri memakan waktu yang sangat lama (Buddhima Indratna, 2008). Untuk mempercepat waktu penurunan konsolidasi pada tanah lunak, PVD dapat digunakan bersamaan dengan preloading untuk mempercepat penurunan (Dennes T. Bergado, 2001).

PVD memiliki potensi besar dalam perkuatan tanah dengan mempercepat proses konsolidasi dan sudah digunakan secara mendunia (Yue-Bao Deng, 2012). Preloading dengan saluran vertikal mempercepat konsolidasi utama tanah lunak karena dua mekanisme. Pertama, saluran air sering ditempatkan dengan jarak yang dekat (dengan jarak 1 hingga 2 m dalam kasus prefabricated vertical drain(PVD), dan dengan demikian panjang maksimum jalur drainase air pori berkurang menjadi sekitar setengah dari jarak PVD, yang biasanya sebagian kecil dari ketebalan lapisan tanah. Kedua, arah aliran air pori berubah dari vertikal (hanya untuk preloading; Gambar 1) menjadi horizontal (untuk prefabricated with vertical drain; Gambar 2). Karena dua efek ini, waktu yang diperlukan untuk mencapai tingkat konsolidasi yang diperlukan berkurang menjadi beberapa bulan, bukan beberapa dekade dalam kasus preloading sendiri (Gambar 3). Fungsi PVD memungkinkan drainase berlangsung secara horizontal melalui jalur drainase yang jauh lebih pendek sehingga laju konsolidasi bisa dipercepat dan waktu konsolidasi dapat dikurangi (J.Chu, 2004).

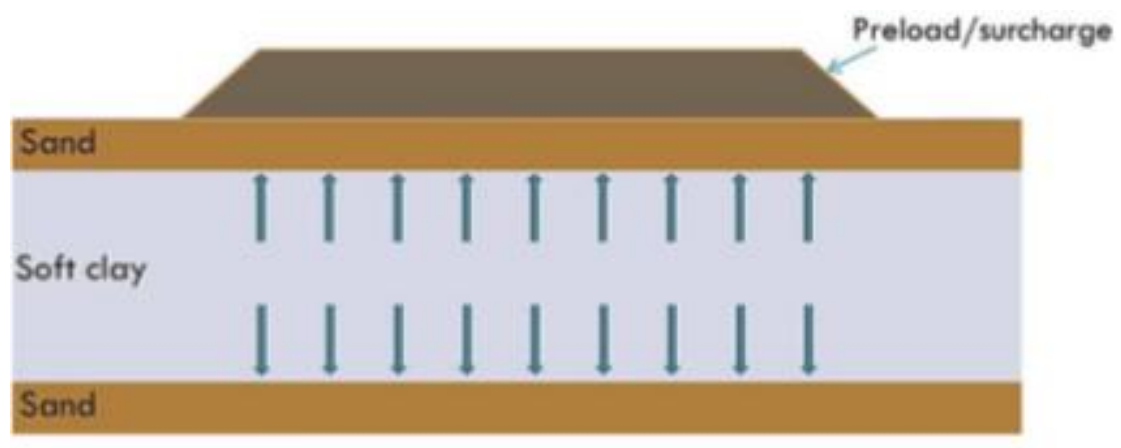

Gambar 1. Preloading 


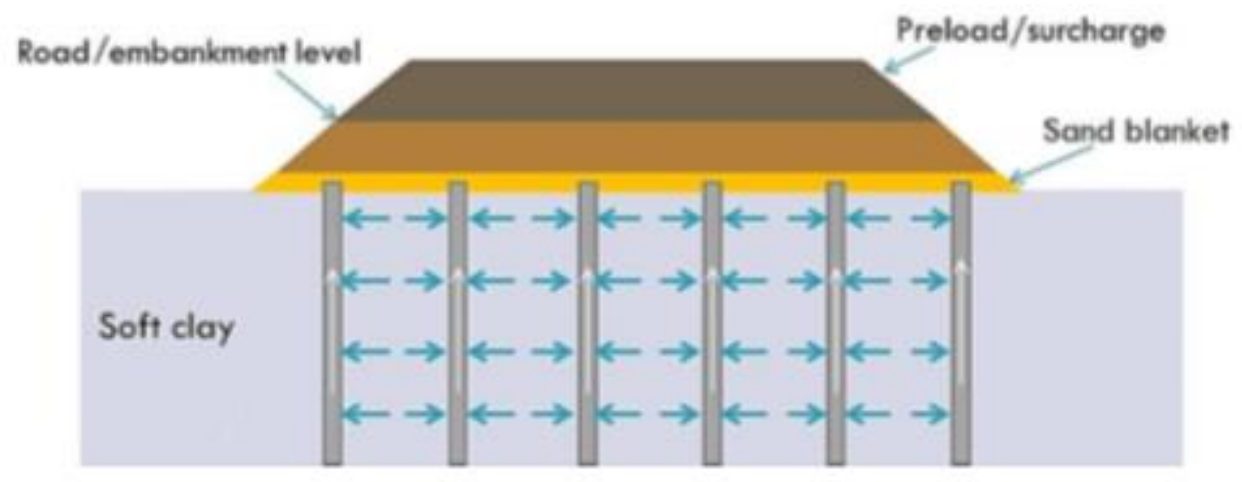

Gambar 2. Preloading dengan saluran vertikal

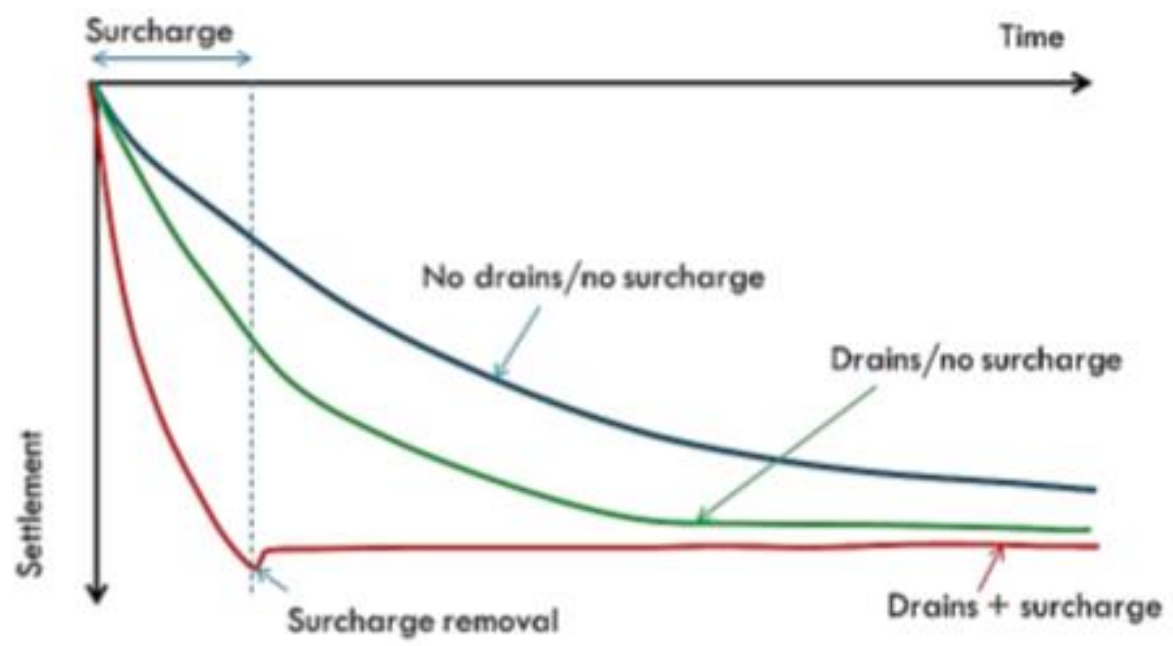

Gambar 3. Tipikal waktu - lengkung penurunan untuk kombinasi yang berbeda dari perbaikan tanah

Pelaksanaan PVD di lapangan biasa menggunakan pola tertentu agar dapat mempermudah . Pola pola yang dipakai untuk pemasangan PVD dilapangan pada umumnya adalah pola persegi dan segitiga dimana rumus yang berlaku untuk mengetahui daerah pengaruh dari PVD adalah:

$$
\begin{gathered}
\mathrm{R}=0,546 S \text { atau } \mathrm{D}=1,13 S \text { (untuk pola bujur sangkar) } \\
\mathrm{R}=0,525 S \text { atau } \mathrm{D}=1,05 S \text { (Untuk pola segitiga) }
\end{gathered}
$$

dengan $\mathrm{D}=$ diameter jangkauan kerja pada PVD , $\mathrm{R}=$ jari jari , $\mathrm{S}=$ jarak dari setiap PVD.
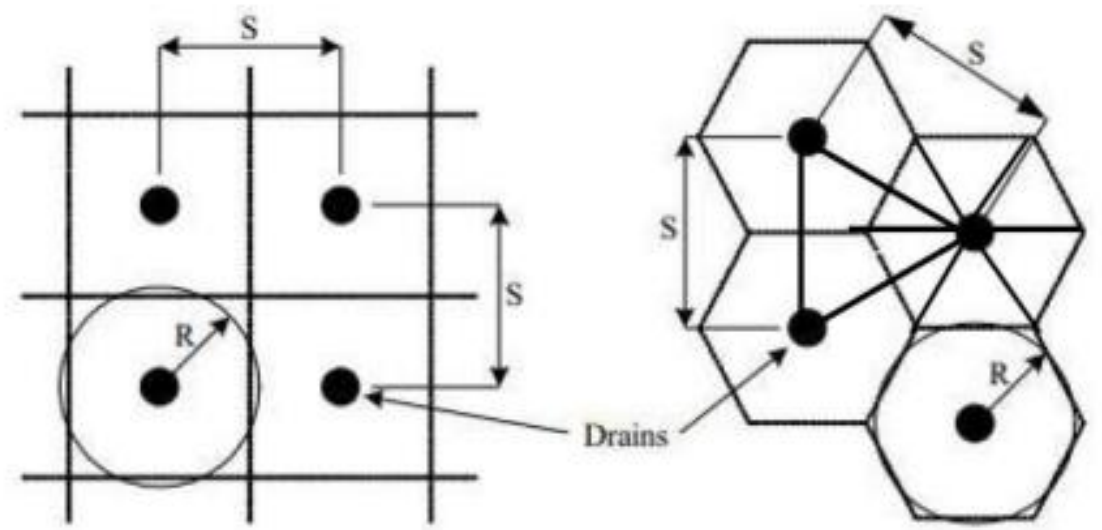

Gambar 4. Pemasangan PVD dalam pola bujur sangkar (kiri) dan segitiga (kanan) 
Pola segitiga dan bujur sangkar disini akan memberikan pengaruh sendiri terhadap kinerja PVD di lapangan. Penurunan lebih seragam adalah pengaruh dari pola segitiga di lapangan sedangkan pola bujur sangkar disini akan lebih mudah dikontrol saat dilapangan. Menurut Han (2015), diameter ekivalen dari suatu PVD dapat dinyatakan dengan persamaan berikut

$$
\mathrm{d}_{\mathrm{c}=} \alpha_{\mathrm{d}} \frac{2(b+t g)}{\pi}
$$

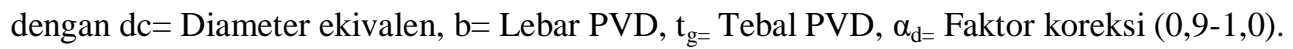

\section{Penurunan konsolidasi}

Konsolidasi merupakan fenomena dalam mekanika tanah yang sering menimbulkan permasalahan geoteknik (Apoji, Fatimatuzahro, \& Pamuji, 2012). Ketika lapisan tanah jenuh mengalami peningkatan tekanan, tekanan air pori meningkat tiba-tiba. Di tanah sangat permeable yang berpasir, drainase yang disebabkan oleh peningkatan tekanan air pori segera berakhir. Penurunan akhirnya dihasilkan karena pengurangan volume massa tanah dan drainase air pori. Karena drainase air pori yang cepat di tanah berpasir, penurunan elastis dan konsolidasi terjadi secara bersamaan (Budhu, 2015).

Ketika lapisan tanah liat yang kompresif jenuh mengalami peningkatan tekanan, penurunan elastis segera terjadi. Karena konduktivitas hidrolik tanah liat secara signifikan lebih kecil daripada pasir, tekanan air pori berlebih yang dihasilkan oleh pembebanan berangsur-angsur hilang dalam periode yang lama. Dengan demikian, perubahan volume yang terkait (yaitu, konsolidasi) di tanah liat dapat berlanjut lama setelah penurunan elastis. Penurunan yang disebabkan oleh konsolidasi dalam tanah liat mungkin beberapa kali lebih besar dari penurunan elastis.

Perhitungan penurunan yang disebabkan oleh konsolidasi satu dimensi menggunakan rumus :

$$
\mathrm{Sc}=\frac{C c H}{1+e 0} \log \left(\frac{\sigma^{\prime} o+\Delta \sigma^{\prime}}{\sigma \prime o}\right)
$$

\section{Indeks pemampatan}

Indeks pemampatan dipakai untuk menghitung nilai dari penurunan berlaku di lapangan sebagai hasil konsolidasi bisa ditetapkan pada kurva yang menunjukan asosiasi antar angka pori serta tekanan yang diperoleh melalui tes konsolidasi pada laboratorium.

Saran Terzaghi dan Peck (1967) menghitung persamaan indeks pemampatan melalui persamaan berikut:

Undisturbed soil

$$
C c=0,009(L L-10)(5)
$$

Remolded

$$
C c=0,007(L L-10)(6)
$$

dengan $\mathrm{LL}=$ batas cair dalam persen.

Beberapa korelasi lainpun tersedia untuk indeks pemampatannya. Pengetesan sudah dilakukan pada berbagai macam tanah lempung. Beberapa korelasi diberikan pada tabel dibawah.

Tabel 1. Hubungan indeks pemampatan Cc

\begin{tabular}{lc}
\hline \multicolumn{1}{c}{ Varian } & Daerah Pemakaian \\
\hline $\mathrm{Cc}=0,007(\mathrm{LL}-9)$ Skempton & Lempung yang terbentuk kembali (remolded) \\
\hline $\mathrm{Cc}=0,01 \mathrm{WN}$ & Lempung Chicago \\
$\mathrm{Cc}=1,15(\mathrm{eo}-0,27)$ Nishida & semua lempung \\
$\mathrm{Cc}=0,3(\mathrm{eo}-0,27)$ nough & tenah kohesif anorganik lanau, lempung berlanau, lempung \\
$\mathrm{Cc}=0,0115 \mathrm{WN}$ & tanah organik gambut, lanau organik, dan lempung \\
$\mathrm{Cc}=0,0046(\mathrm{LL}-9)$ & Lempung brazilia \\
$\mathrm{Cc}=0,75(\mathrm{eo}-0,5)$ & Tanah dengan plastisitas rendah \\
$\mathrm{Cc}=0,0208 \mathrm{eo}+0,0083$ & Lempung Chicago \\
$\mathrm{Cc}=0,256 \mathrm{eo}+0,0107$ & Semua lempung \\
\hline
\end{tabular}


(Sumber: (Das, Principles of Geotechnical Engineering, 2009))

\section{Indeks pemuaian}

Penentuan indeks pemuaian biasanya dilakukan di laboratorium, dan indeks pemuaian lebih kecil dari indeks pemampatan. Pada umumnya,

$$
\mathrm{C}_{\mathrm{s}} \simeq \frac{1}{5} \operatorname{sampai} \frac{1}{10} \mathrm{C}_{\mathrm{c}}
$$

Batas cair, batasplastis, indeks pemampatan, serta indeks pemuaian untuk tanah yang masih belum rusak strukturnya dalam tabel dibawah

Tabel 2. Pemampatan dan pemuaian tanah asli

\begin{tabular}{lcccc}
\hline \multicolumn{1}{c}{ Tanah } & $\begin{array}{c}\text { Batas } \\
\text { cair }\end{array}$ & $\begin{array}{c}\text { Batas } \\
\text { plastis }\end{array}$ & $\begin{array}{c}\text { Indeks } \\
\text { pemampatan } \\
\text { (Cc) }\end{array}$ & $\begin{array}{c}\text { Indeks } \\
\text { Pemuaian } \\
\text { (Cs) }\end{array}$ \\
\hline Lempung Boston Blue & 41 & 20 & 0,35 & 0,07 \\
Lempung Chicago & 60 & 20 & 0,4 & 0,07 \\
Lempung Ft gordon Georgia & 51 & 26 & 0,12 & \\
Lempung New Orleans & 80 & 25 & 0,3 & 0,05 \\
Lempung Montana & 60 & 28 & 0,21 & 0,05 \\
\hline
\end{tabular}

(Sumber: (Das, Principles of Geotechnical Engineering, 2009))

\section{Faktor waktu konsolidasi}

Perhitungan faktor waktu konsolidasi di lapangan yang dibutuhkan menggunakan rumus berikut :

$$
\mathrm{T}_{\mathrm{v}} \quad: \frac{c v t}{H^{2} d r}
$$

dengan $\mathrm{Cv}=$ Koefisien konsolidasi arah vertical, $\mathrm{t}$ = waktu yang dibutuhkan, $\mathrm{H}^{2}=$ tebal lapisan yang dilalui air. Untuk Perhitungan faktor waktu arah radial / horizontal menggunakan rumus :

$$
\operatorname{Tr}=\frac{C h * t}{d e^{2}}
$$

dengan $\mathrm{Ch}=$ Koefisien konsolidasi arah horizontal, $\mathrm{t}=$ waktu konsolidasi, $\mathrm{de}=$ Diameter ekivalen.

\section{Koefisien konsolidasi}

Persamaan yang diberikan untuk Uv yang bervariasi dari 0\% sampai 100\% sebagai berikut:

$$
\mathrm{Uv}=\frac{\sqrt{\frac{4 . T v}{\pi}}}{\left(1+\left(\frac{4 T v}{\pi}\right)^{2.8}\right)^{0.179}}
$$

Sedangkan, menentukan derajat konsolidasi arah horizontalnya menggunakan metode equal strain consolidation, dengan rumus

$$
\mathrm{Ur}=1-\exp \left(\frac{-8 T r}{m}\right)
$$

Dimana

$$
\mathrm{m}=\left(\frac{n^{2}}{n^{2}-1}\right) \ln n-\frac{3 n^{2}-1}{4 n^{2}}
$$

dan

$$
\mathrm{n}=\frac{d e}{d c}
$$

dengan $\operatorname{Tr}=$ faktor waktu akibat konsolidasi radial, $\mathrm{d}_{\mathrm{e}}=$ daerah pengaruh diameter $\mathrm{PVD}, \mathrm{d}_{\mathrm{c}}=$ diameter ekivalen PVD. 
Perbandingan penurunan tanah dalam suatu waktu disebut juga derajat konsolidasi (U). Menurut Carillo (1942) persamaan derajat konsolidasi di tanah yang terstabilisasi dengan sistem PVD adalah berikut :

$$
\mathrm{U}=1-(1-\mathrm{Uh})(1-\mathrm{Uv})
$$

dengan $\mathrm{U}=$ Derajat konsolidasi rata-rata, $\mathrm{Uh}=$ Derajat konsolidasi arah horizontal $/$ radial, Uv $=$ Derajat konsolidasi arah vertikal.

\section{Metode Asaoka}

Metode Asaoka (1978) termasuk salah satu metode untuk mengobservasi konsolidasi satu arah yang paling popular. Karena pada metode ini penurunan tanah aktual dapat diprediksi tanpa dibutuhkannya data-data laboratorium, yang digunakan pada analisis di metode ini yaitu hasil pengamatan lapangan, seperti panjang drainase, tekanan air pori, regangan maksimum tanah, dan koefisien konsolidasi. Pada metode asaoka ini, prediksi penurunannya didapat dari metode curve fitting.

Di lapangan penurunan direkam oleh instrument settlement plate. Agar dapat memprediksi penurunan akhirnya dari data penurunan ini , maka harus dipilih data data penurunan ini, hingga akhirnya didapat nilai penurunan $\rho_{1}$, $\rho_{2}, \rho_{3}, \ldots, \rho_{\mathrm{n}}$ dengan interval waktu $\Delta$ t. Lalu nilai dari $\rho_{\mathrm{n}}$ dan nilai $\rho_{\mathrm{n}-1}$ di plot sehingga membentuk garis lurus. Penurunan akhir $\left(\rho_{\mathrm{f}}\right)$ adalah pertemuan antar garis $\rho_{\mathrm{n}}=\rho_{\mathrm{n}-1}$ (bersudut $45^{\circ}$ ) dengan garis regresi dari titik $\rho_{\mathrm{n}}$ vs $\rho_{\mathrm{n}-1}$. Data penurunan akhir ini didapat pada konsolidasi $100 \%$.

\section{METODE PENELITIAN}

Penelitian ini dilakukan dengan mencari data tanah. Data tanah untuk sebuah penelitian merupakan suatu hal yang harus ada dan sangat dibutuhkan. Data tanah pada umumnya adalah berupa SPT (Standard Peneration Test). CPT (Cone Peneration Test), data lab, serta data hasil test di lapangan. Pada penulisan studi kali ini data tanah yang digunakan berasal dari Jakarta Timur. Data tanah yang digunakan berupa data boringlog dengan mengambil jenis tanah serta nilai N-SPTnya, data lab pada kedalaman tertentu, serta data settlement recording. Ketiga data inilang yang menjadi dasar dari penelitian kali ini. Metode yang digunakan dalam penelitian ini adalah metode konsolidasi satu dimensi dari Terzaghi, metode elemen hingga menggunakan program, dan juga metode asaoka.

\section{Diagram alir penelitian}

Gambar 5. adalah diagram penelitian yang dilakukan dimulai dari tahap penelitian, analisis, hingga mencari kesimpulan. 


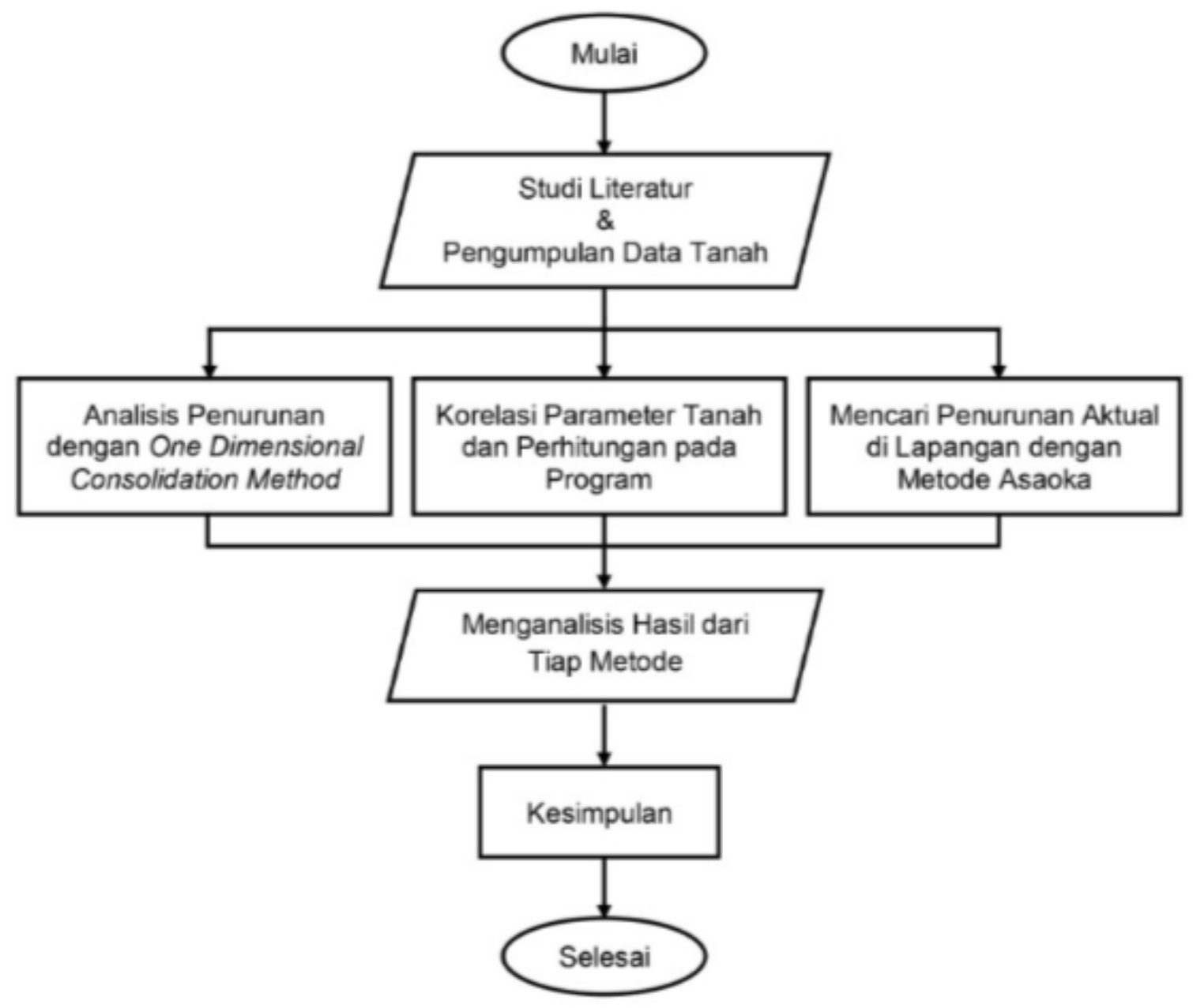

Gambar 5. Diagram alir penelitian

\section{HASIL DAN PEMBAHASAN.}

\section{Perhitungan penurunan dari tanah menurut teori terzaghi}

Perhitungan penurunan tanah disini menggunakan persamaan one dimensional consolidation oleh Terzaghi. Tabel 3 menunjukan perhitungan penurunan tanah yang terjadi berdasarkan perhitungan menggunakan persamaan one dimensional consolidation.

Tabel 3. Hasil perhitungan penurunan

\begin{tabular}{ccccccccc}
\hline Lapisan & $\begin{array}{c}\text { Kedalaman } \\
\text { Perlapisan } \\
(\mathrm{m})\end{array}$ & $\begin{array}{c}\text { Ketebalan } \\
\text { Tanah }(\mathrm{H})\end{array}$ & $\begin{array}{c}\gamma \text { dry } \\
(\mathrm{KN} / \mathrm{m} 3)\end{array}$ & $\begin{array}{c}\sigma \\
(\mathrm{KN} / \mathrm{m} 2)\end{array}$ & $\begin{array}{c}\Delta \sigma \\
(\mathrm{KN} / \mathrm{m} 2)\end{array}$ & $\mathrm{Cc}$ & $\mathrm{e} 0$ & $\mathrm{~S}(\mathrm{~m})$ \\
\hline 1 & $0,00-1,00$ & 1 & 13,5 & 13,5 & 90 & 1,078 & 2,68 & 0,259 \\
2 & $1,00-11,00$ & 10 & 13,5 & 48,5 & 90 & 1,078 & 2,68 & 1,335 \\
3 & $11,00-15,00$ & 4 & 13,5 & 62,5 & 90 & 1,078 & 2,68 & 0,454 \\
\hline
\end{tabular}




\section{Menghitung waktu penurunan tanpa PVD}

Analisa perhitungan analisis ini didasari oleh teori 1 dimensi terzaghi. Penelitian ini mencari waktu penurunan tanpa PVD hingga mencapai derajat konsolidasi 90\%. Hasil perhitungan dapat dilihat pada tabel 4

Tabel 4. Waktu penurunan tanpa PVD

\begin{tabular}{|c|c|c|c|c|}
\hline Waktu (t) & $\begin{array}{c}\text { Koefisien } \\
\text { Konsolidasi Arah } \\
\text { Vertikal }(\mathrm{Cv})\end{array}$ & $\mathrm{Hdr} / 2$ & $\begin{array}{c}\text { Faktor } \\
\text { Waktu } \\
\text { konsolidasi } \\
\text { arah } \\
\text { vertikal }\end{array}$ & $\begin{array}{c}\text { Derajat } \\
\text { konsolidasi } \\
\text { arah } \\
\text { vertikal }\end{array}$ \\
\hline (Hari) & (m2/hari) & (m) & $(\mathrm{Tv})$ & \\
\hline 0 & 0,000864 & 7 & 0,000 & 0,000 \\
\hline 2 & 0,000864 & 7 & 0,000 & 0,007 \\
\hline 100 & 0,000864 & 7 & 0,002 & 0,047 \\
\hline 500 & 0,000864 & 7 & 0,009 & 0,106 \\
\hline 1000 & 0,000864 & 7 & 0,018 & 0,150 \\
\hline 2000 & 0,000864 & 7 & 0,035 & 0,212 \\
\hline 5000 & 0,000864 & 7 & 0,088 & 0,335 \\
\hline 10000 & 0,000864 & 7 & 0,176 & 0,473 \\
\hline 20000 & 0,000864 & 7 & 0,353 & 0,658 \\
\hline 30000 & 0,000864 & 7 & 0,529 & 0,780 \\
\hline 40000 & 0,000864 & 7 & 0,705 & 0,858 \\
\hline 41000 & 0,000864 & 7 & 0,723 & 0,864 \\
\hline 46000 & 0,000864 & 7 & 0,811 & 0,890 \\
\hline 48000 & 0,000864 & 7 & 0,846 & 0,899 \\
\hline 48300 & 0,000864 & 7 & 0,852 & 0,900 \\
\hline
\end{tabular}

\section{Menghitung waktu penurunan dengan diterapkannya PVD}

PVD yang dipakai memiliki lebar $0.1 \mathrm{~m}$, ketebalan $3.6 \mathrm{~mm}$, Diameter $1.2 \mathrm{~m}$. Perhitungan ini memiliki cara yang serupa dengan tanpa adanya PVD. Namun disini ada diterapkan koefisien konsolidasi arah horizontal/radial. Perhitungan kali ini dimulai dengan jarak spasi antar PVD bervariasi dari 1m, 1.2m, 1.5m, 1.7m, $2 \mathrm{~m}$. Contoh perhitungan dapat dilihat pada table 4 untuk jarak $1 \mathrm{~m}$ pada pola segitiga, dan hasil akhir dapat dilihat pada table 5 
Tabel 5. Waktu penurunan dengan jarak spasi $1 \mathrm{~m}$

\begin{tabular}{|c|c|c|c|c|c|c|c|c|}
\hline $\begin{array}{c}\text { Waktu } \\
\text { (t) }\end{array}$ & $\begin{array}{c}\text { Koefisien } \\
\text { Konsolidasi } \\
\text { Arah } \\
\text { Vertikal } \\
\text { (Cv) } \\
\text { (m2/hari) }\end{array}$ & $\mathrm{Hdr} / 2$ & $\begin{array}{c}\text { Faktor } \\
\text { Waktu } \\
\text { konsolidasi } \\
\text { arah } \\
\text { vertikal } \\
\text { (Tv) }\end{array}$ & $\begin{array}{c}\text { Derajat } \\
\text { konsolidasi } \\
\text { arah } \\
\text { vertikal } \\
\text { (Uv) }\end{array}$ & $\begin{array}{l}\text { Koefisien } \\
\text { Konsolidasi } \\
\text { Arah } \\
\text { Horizontal } \\
\text { (Ch) }\end{array}$ & $\begin{array}{c}\text { Faktor } \\
\text { Waktu } \\
\text { konsolidasi } \\
\text { arah } \\
\text { horizontal } \\
\text { (Th) } \\
\end{array}$ & $\begin{array}{c}\text { Derajat } \\
\text { konsolidasi } \\
\text { arah } \\
\text { horizontal } \\
\text { (Uh) }\end{array}$ & $\begin{array}{c}\text { Derajat } \\
\text { konsolidasi } \\
\text { gabungan } \\
\text { (U) }\end{array}$ \\
\hline 0 & 0,000864 & 7 & 0,00 & 0,00 & 0,008640 & 0,00 & 0,00 & 0,00 \\
\hline 1 & 0,000864 & 7 & 0,00 & 0,00 & 0,008640 & 0,01 & 0,03 & 0,04 \\
\hline 3 & 0,000864 & 7 & 0,00 & 0,01 & 0,008640 & 0,02 & 0,09 & 0,10 \\
\hline 4 & 0,000864 & 7 & 0,00 & 0,01 & 0,008640 & 0,03 & 0,12 & 0,13 \\
\hline 5 & 0,000864 & 7 & 0,00 & 0,01 & 0,008640 & 0,04 & 0,15 & 0,16 \\
\hline 6 & 0,000864 & 7 & 0,00 & 0,01 & 0,008640 & 0,05 & 0,17 & 0,18 \\
\hline 7 & 0,000864 & 7 & 0,00 & 0,01 & 0,008640 & 0,05 & 0,20 & 0,21 \\
\hline 8 & 0,000864 & 7 & 0,00 & 0,01 & 0,008640 & 0,06 & 0,22 & 0,24 \\
\hline 9 & 0,000864 & 7 & 0,00 & 0,01 & 0,008640 & 0,07 & 0,25 & 0,26 \\
\hline 10 & 0,000864 & 7 & 0,00 & 0,01 & 0,008640 & 0,08 & 0,27 & 0,28 \\
\hline 20 & 0,000864 & 7 & 0,00 & 0,02 & 0,008640 & 0,16 & 0,47 & 0,48 \\
\hline 30 & 0,000864 & 7 & 0,00 & 0,03 & 0,008640 & 0,24 & 0,61 & 0,62 \\
\hline 40 & 0,000864 & 7 & 0,00 & 0,03 & 0,008640 & 0,31 & 0,72 & 0,73 \\
\hline 50 & 0,000864 & 7 & 0,00 & 0,03 & 0,008640 & 0,39 & 0,80 & 0,80 \\
\hline 55 & 0,000864 & 7 & 0,00 & 0,04 & 0,008640 & 0,43 & 0,83 & 0,83 \\
\hline 60 & 0,000864 & 7 & 0,00 & 0,04 & 0,008640 & 0,47 & 0,85 & 0,86 \\
\hline 65 & 0,000864 & 7 & 0,00 & 0,04 & 0,008640 & 0,51 & 0,87 & 0,88 \\
\hline 70 & 0,000864 & 7 & 0,00 & 0,04 & 0,008640 & 0,55 & 0,89 & 0,90 \\
\hline
\end{tabular}

Tabel 6. Hasil akhir PVD pola segitiga dan bujur sangkar

\begin{tabular}{ccccccc}
\hline \multirow{2}{*}{ Segitiga } & Jarak (m) & 1 & 1.2 & 1.5 & 1.7 & 2 \\
& Waktu (hari) & 70 & 110 & 190 & 260 & 370 \\
\multirow{3}{*}{ Bujur Sangkar } & Jarak (m) & 1 & 1.2 & 1.5 & 1.7 & 2 \\
& Waktu (hari) & 85 & 130 & 230 & 300 & 450 \\
\hline
\end{tabular}

Grafik dari waktu penurunan dengan jarak yang bervariasi ini dapat dilihat pada gambar 5 untuk pola setiga dan gambar 6 untuk pola bujur sangkar

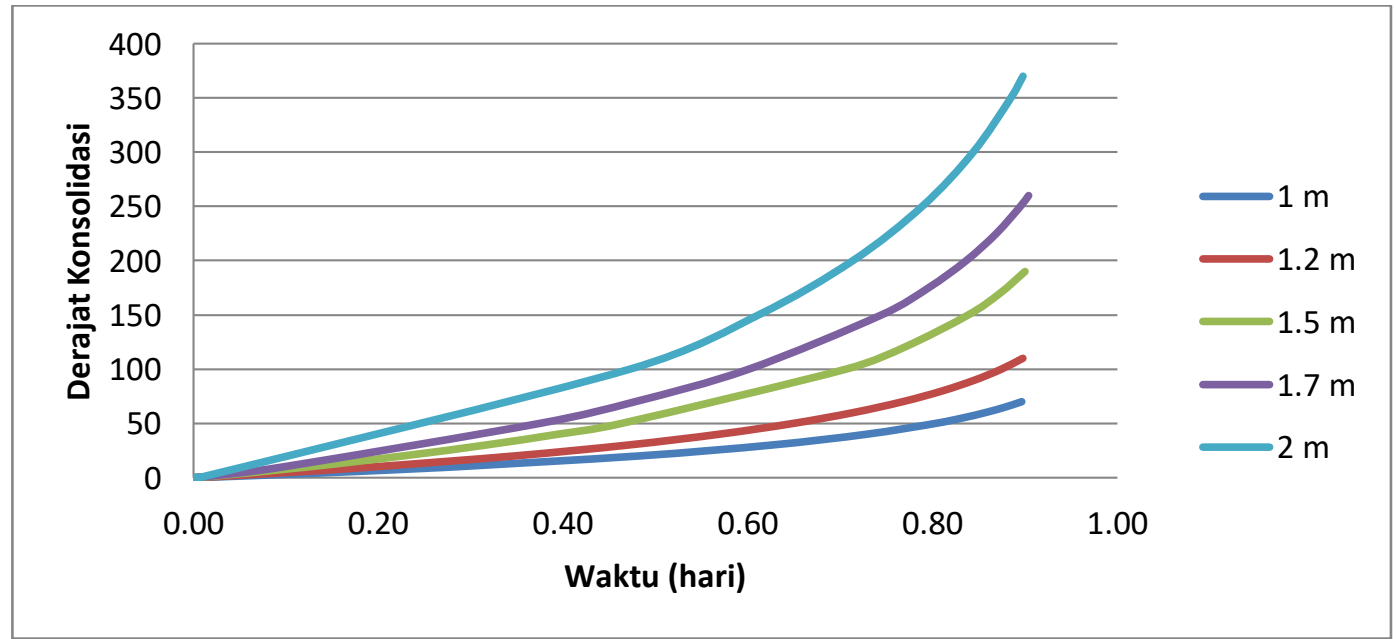

Gambar 6. Perbandingan waktu antar jarak tiap PVD pada pola segitiga 


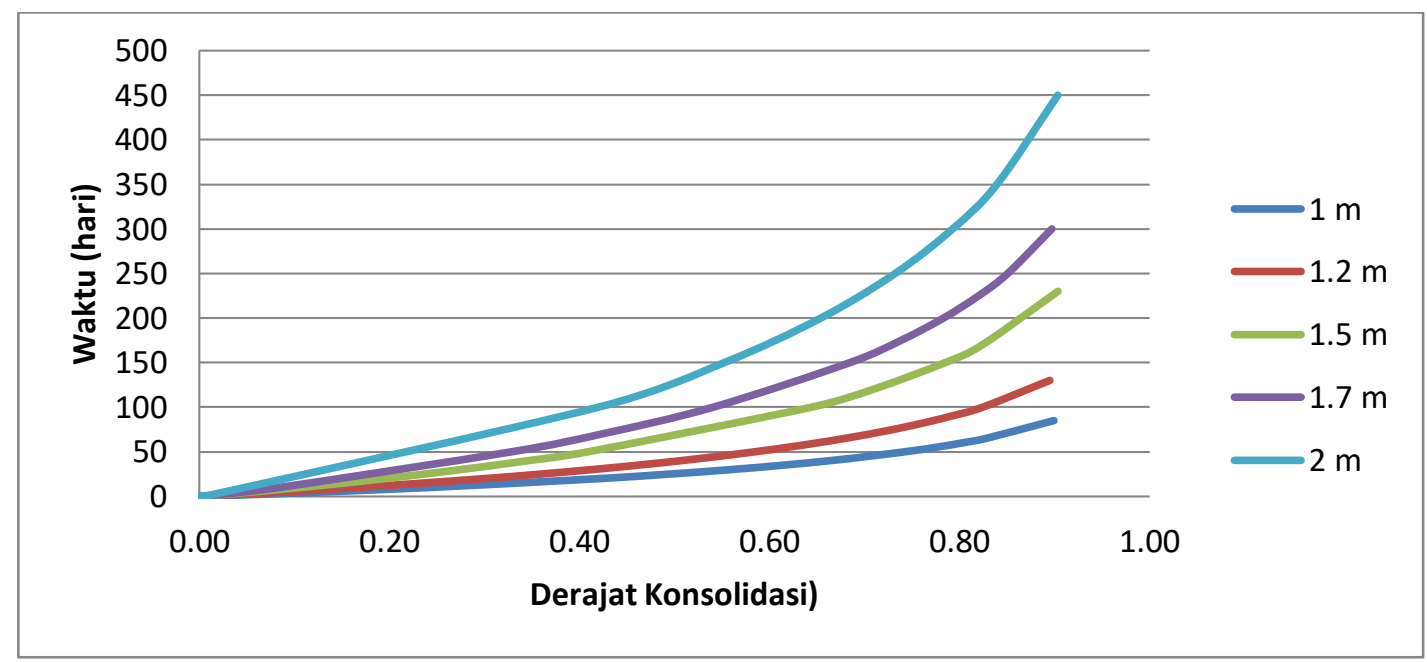

Gambar 7. Perbandingan waktu antar jarak tiap PVD pada pola bujur sangkar

\section{Metode Elemen hingga menggunakan program}

Pada program plaxis 2D, tanah digunakan dengan tipe soft-soil model dan permodelan tanah tanpa PVD dapat dilihat seperti pada gambar 6 .

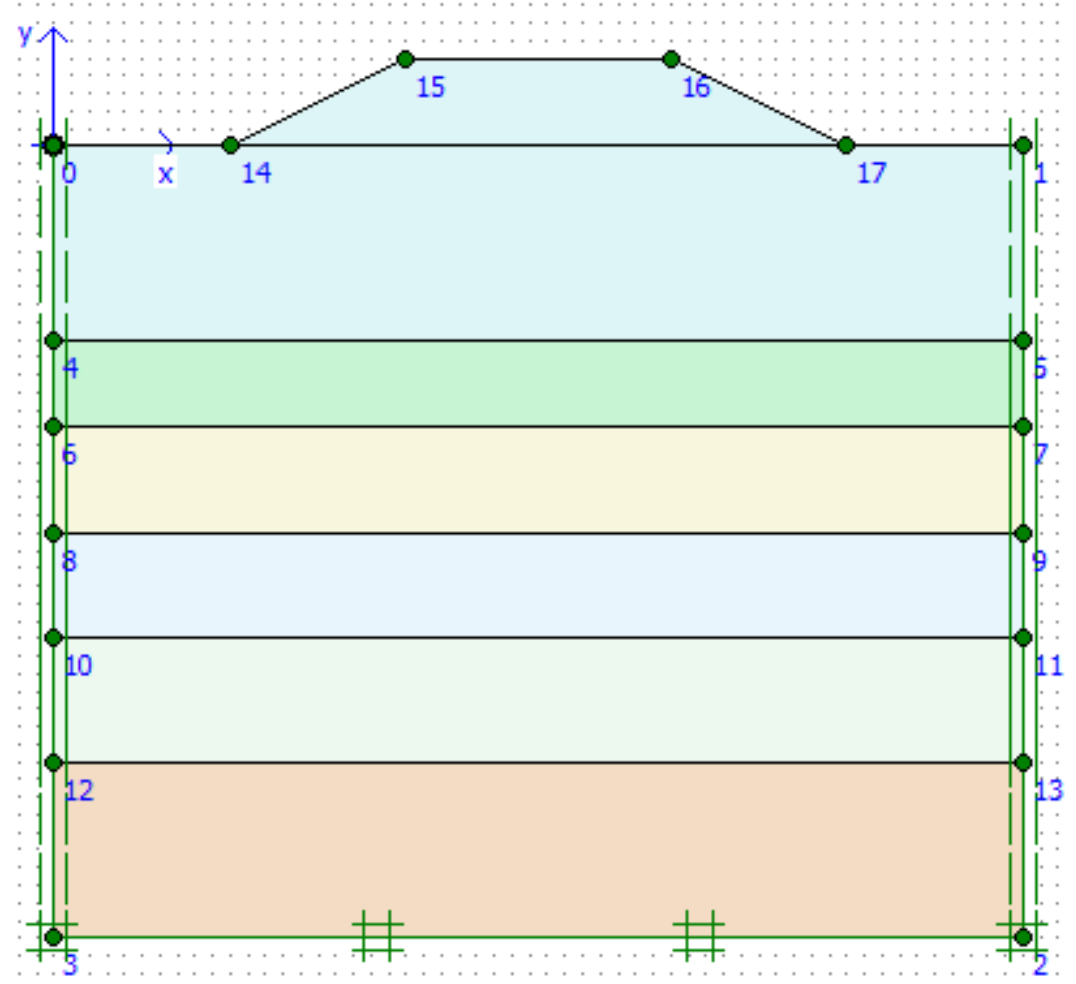

Gambar 8. Permodelan tanah serta timbunan pada plaxis

Hasilnya penurunan yang terjadi sebesar 2.304m dalam waktu 39930 hari, grafik penurunan dapat dilihat pada gambar 7. 


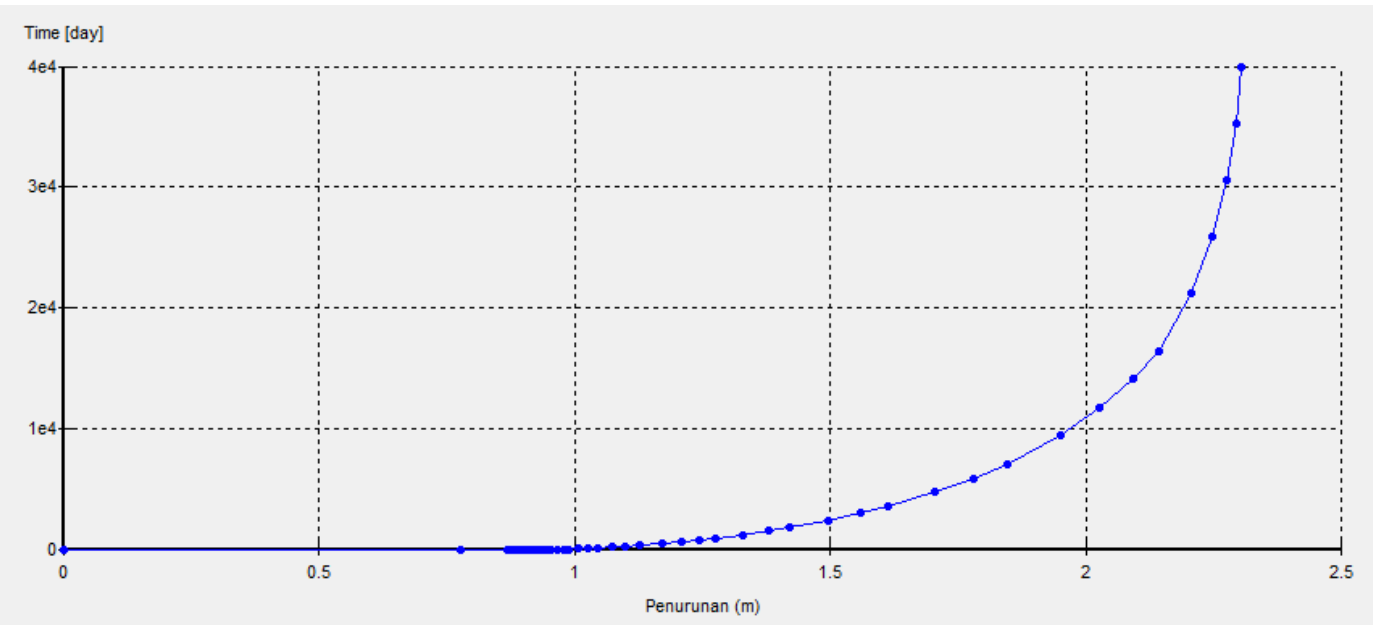

Gambar 9. Kurva penurunan dan waktu yang terjadi

Selanjutnya di tes pada program Plaxis 2D , permodelan tanah dengan PVD menggunakan timbunan bertahap, permodelan tanah dapat dilihat pada gambar 8 .

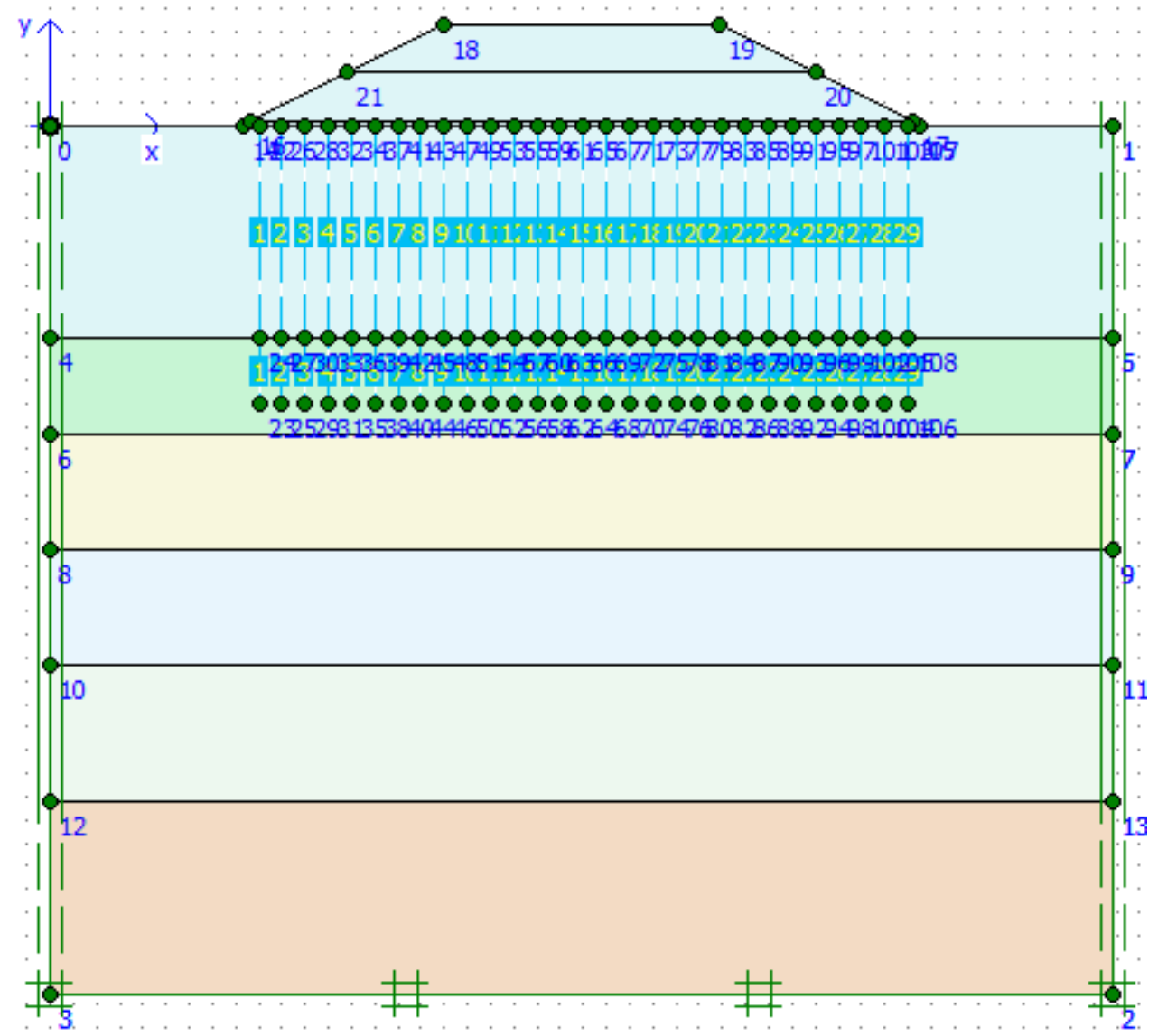

Gambar 10. Permodelan tanah dengan PVD dan timbunan bertahap

Hasil dari diaplikasikannya PVD pada tanah ini menyebabkan penurunan yang terjadi lebih cepat dalam waktu 130 hari, kutvanya dapat dilihat pada gambar 9 . 


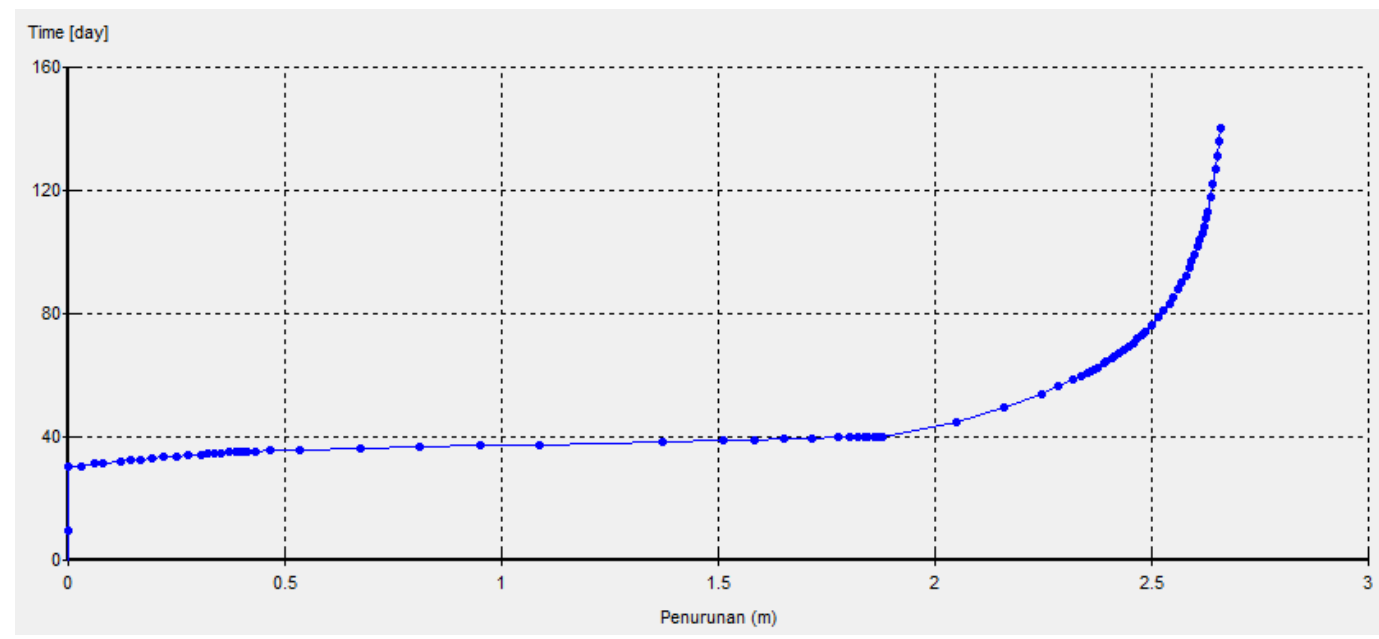

Gambar 11. Kurva waktu penurunan setelah PVD di aplikasikan pada tanhah

\section{Metode Asaoka}

Pada metode ini, data yang digunakan adalah data settlement recording dari lapangan untuk dicari penurunan aktualnya, untuk grafik dari metode ini dapat dilihat pada Gambar 12.

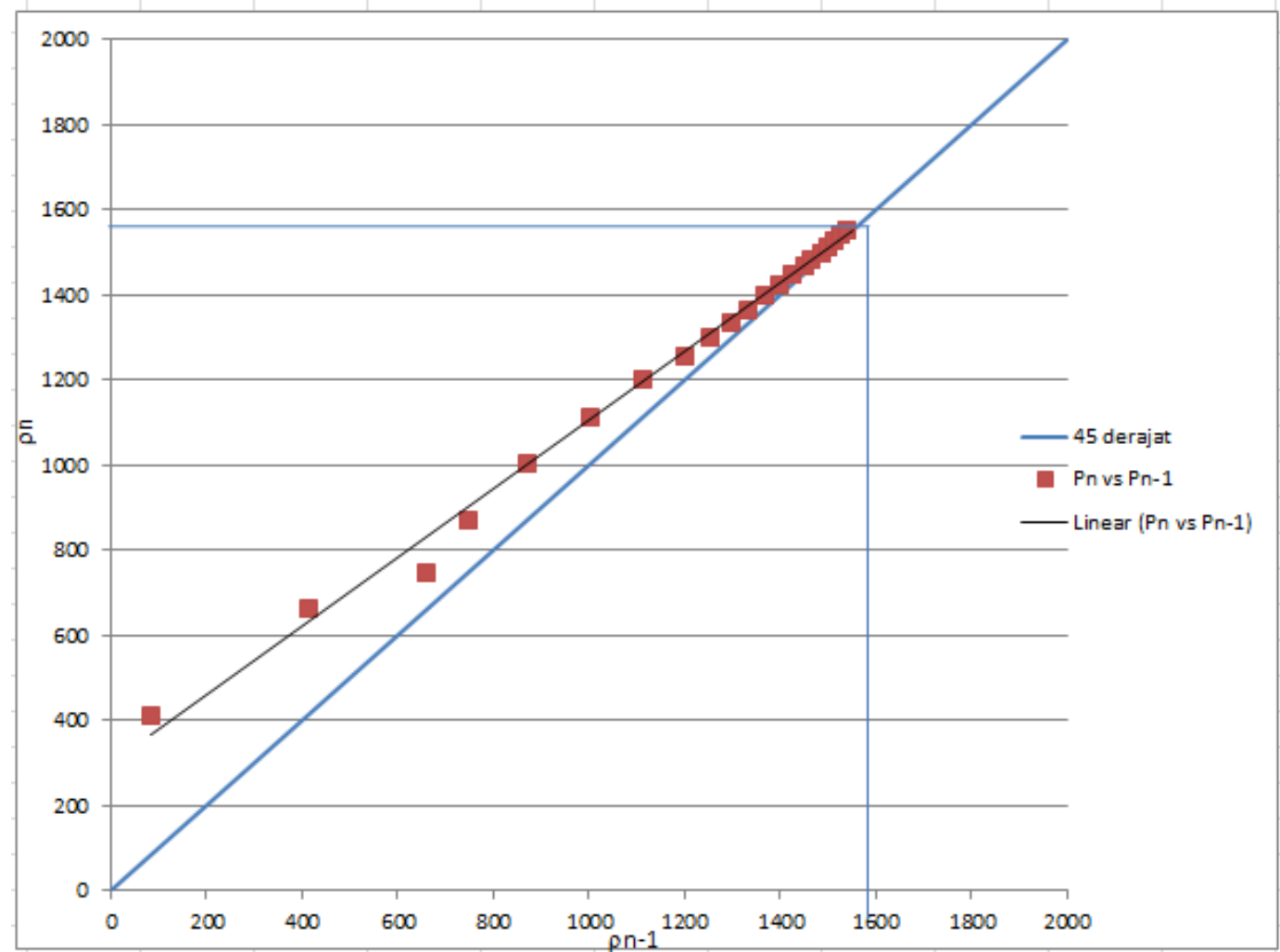

Gambar 12. Grafik penurunan sesuai data lapangan pada metode asaoka

Dari data grafik ini dapat diambil hasil penurunan pada derajat konsolidasi 90\% sebesar 1422 dalam waktu 102 hari. 


\section{KESIMPULAN DAN SARAN}

\section{Kesimpulan}

Dari hasil penelitian yang dilakukan, diperoleh kesimpulan berupa :

1. Penurunan yang terjadi akibat perhitungan analisis sebesar $2.048 \mathrm{~m}$ sedangkan pada program metode elemen hingga sebesar $2.304 \mathrm{~m}$, dan pada hasil metode Asaoka mendapatkan penurunan sebesar $1.422 \mathrm{~m}$. Penurunan yang berbeda antara penurunan aktual dan analisis ini disebabkan oleh data Compression Index yang tidak cukup banyak pada sample data lab, sehingga menyebabkan ketidak akuratan perhitungan analisis.

2. Waktu yang penurunan untuk mencapai derajat konsolidasi $90 \%$ tanpa adanya aplikasi PVD selama 48300 hari, sedangkan setelah diaplikasikannya PVD pada tanah ini waktu untuk mencapai derajat konsolidasi $90 \%$ selama 110 hari saja. Pada metode asaoka didapatkan waktu yang dibutuhkan untuk sampai derajat konsolidasi $90 \%$ selama 102 hari.

3. Dilihat dari grafik setiap jarak PVD yang diterapkan pada analisis, diambil jarak $1.2 \mathrm{~m}$ dengan pola segitiga sebagai PVD yang paling efektif karena hasilnya yang tidak memiliki jangka waktu yang jauh dengan $1 \mathrm{~m}$ namun memiliki rentang waktu yang cukup jauh dengan $1.5 \mathrm{~m}$.

\section{Saran}

Dari analisis yang dilakukan, diharapkan adanya hasil laboratorium yang lebih lengkap data pengujiannya agar hasil perhitungan dari analisanya dapat lebih menyerupai dengan hasil pada lapangan

Untuk penelitian berikutnya, disarankan juga untuk menggunakan metode lain agar waktu penurunan dapat dipercepat seperti vaccum preloading, atau dynamic compaction pada timbunannya.

\section{DAFTAR PUSTAKA}

Anissa Maria Hidayati, Made Dodiek Wirya Ardana. "Kombinasi preloading dan menggunakan prefabricated vertical drains untuk mempercepat konsolidasi tanah lempung lunak." Jurnal Ilmiah Teknik Sipil Vol. 12, No 2 (2006).

Apoji, Dayu, Rahmatyar Fatimatuzahro and M. Dwi Pamuji. "JURNAL TEKNIK SIPIL." Prediksi Penurunan Tanah Menggunakan Prosedur Observasi Asaoka (2012).

Buddhima Indratna, Cholachat Rujikiatkamjorn. "Effect of Partially Penetrating Prefabricated Vertical Drains and Loading Pattens on Vacuum Consolidation." GeoCongress (2008).

Budhu, Muni. Soil Mechanics Fundamentals. John Wiley \& Sons, (2015).

Das, Braja M. Principles of Geotechnical Engineering. Stamford: CL Engineering, (2009).

Dennes T. Bergado, A.s. Balasubramniam, R. Jonathan Fannin, and Robert D. Holtz. "Prefabricated vertical drains (PVDs) in soft bangkok clay ." (2001).

J.Chu, M.W. Bo. "Practical considerations for using vertical drains in soil improvement projects." (2004).

M. W. BO, A. Arulrajah. H. Nikraz. "Preloading and prefabricated vertical drains design for foreshore land reclamation projects." Ground Improvement (2007).

Sakleshpu, Venkata Abhishek, Rodrigo Salgado and Monica Prezzi. "Geotechnical Engineering." Ground Engineering using prefabricated vertical drains: A Review (2018)

Yue-Bao Deng, Kang-He Xie, Meng-Meng Lu, Hai-Bing Tao, Gan-Bin Liu. "Consolidation by prefabricated vertical drains considering the time dependent well resistance." Geotextiles and Geomembranes (2012). 
